\title{
Technical Issues in Craniomaxillofacial Distraction Osteogenesis: A Case Series
}

Khairul Bariah Chi Adam ${ }^{1}$, Firdaus Hariri ${ }^{2}$, Lim Kwong Cheung ${ }^{3}$, Syed Nabil ${ }^{4}$, Aung Lwin Oo ${ }^{1}$, Zainal Ariff Abdul Rahman'.

${ }^{1}$ Oral \& Maxillofacial Surgery Unit, Kulliyyah of Dentistry, International Islamic University, 25200 Kuantan, Pahang, Malaysia ${ }^{2}$ Department of Oro-Maxillofacial Surgical and Medical Sciences, Faculty of Dentistry, University of Malaya, 50603 Kuala Lumpur, Malaysia ${ }^{3}$ Discipline of Oral and Maxillofacial Surgery, Faculty of Dentistry, The University of Hong Kong, Hong Kong Special Administrative Region ${ }^{4}$ Department of Oral and Maxillofacial Surgery, Faculty of Dentistry, National University of Malaysia, 50300 Kuala Lumpur, Malaysia

\begin{abstract}
Distraction osteogenesis allows superior skeletal advancement compared to conventional surgical osteotomy. It can be considered as a reliable and predictable surgical procedure and is widely used to correct the craniomaxillofacial bone discrepancy. Nevertheless, the outcome is technically dependent and requires comprehensive peri-operative assessment, preparation, and precision in application. The objective of this study is to highlight some important technical issues in distraction osteogenesis when the technique is indicated in various craniomaxillofacial regions and at the same time to discuss the options of preventing and overcoming these technical complications based on our experience and relevant literature. Important technical issues on the application of distraction osteogenesis in 5 different craniomaxillofacial regions were selectively highlighted based on the completed cases in one centre. Potential complications and its prevention methods were documented and discussed. The 5 highlighted regions of craniomaxillofacial distraction osteogenesis were alveolar, mandibular, cleft maxilla, craniofacial and facial cleft. Technical issues and complications were mostly device related and associated with anatomical limitations and surgical technique. Nevertheless, these complications are preventable and can be appropriately managed. From the literature and our experience, the technical aspects vary according to its application in different craniomaxillofacial regions. Preventing the potential complications contribute to the success of its application. This article also discussed the concept of Ihsan application in the medical field, to achieve the best of treatment in terms of delivery and technical preparation for the patients.
\end{abstract}

KEYWORDS: distraction osteogenesis, craniomaxillofacial surgery, technical issues, Complications.

\subsection{INTRODUCTION}

The history of distraction osteogenesis (DO) started back as early as 1905 when it was first reported in the field of orthopedic surgery when the technique was used for femoral lengthening. ${ }^{1}$ The concept was not that popular until Gavril Ilizarov revolutionized the technique by publishing a series of tensionstress principles thus embarking to the full clinical application of this technique worldwide. ${ }^{2-4}$ In a craniomaxillofacial area, a number of animal researches involving DO were initially published in the $1970 \mathrm{~s}^{5,6}$ followed by a landmark study of its first application in human was reported by McCarthy for mandibular lengthening in four patients. ${ }^{7}$

Following the successful cases in human jaw, the

Khairul Bariah Chi Adam

Oral \& Maxillofacial Surgery Unit, Kulliyyah of Dentistry,

International Islamic Úniversity,

Kuantan Campus.

Email: bariah@iium.edu.my technique has been widely used not only for mandibular lengthening but almost every aspect of craniomaxillofacial bone area. Currently, it is widely used as an alternative to bone augmentation procedure for atrophic alveolar ridge,cleft maxillary advancement, mandibular lengthening in micrognathia, temporomandibular joint (TMJ) reconstruction and craniomaxillofacial surgery. 8,9

Distraction osteogenesis is a biological process that involves manipulation of callus formation between the segmentalized osseous surfaces that are gradually separated by incremental traction. ${ }^{8}$ It is initiated when forces are applied to separate the segments and continues as long as the tissues of the callus that forms between the segments are stretched, forming bone parallel to the direction of the vector of distraction. The main principles of DO can be systematically studied and described in specific phases which consist of bone osteotomy, latency, activation and consolidation stage as shown in the explanation chart below.

Studies on the technique's three important phases namely latency, activation, and consolidation period have been continuously conducted and the biological outcomes have been persistently proved 
predictable. ${ }^{10}$ Recently, there are various systems commercially available in the market to provide surgeons with the best option to suit the specific indication for an individual case, thus making the technique a very technical - dependent. Furthermore, as distraction osteogenesis can be performed in both pediatric and adult patients, different issues pertaining to the different group of patients need to be addressed carefully.

The objective of this study is to highlight some important technical issues in the application of distraction osteogenesis in various craniomaxillofacial regions and to discuss the options of preventing and overcoming these technical complications based on the relevant literature.

\subsection{METHODS}

Five completed cases of distraction osteogenesis in 5 different craniomaxillofacial regions were selected from Department of Oral and Maxillofacial Surgery, University Malaya Medical Center. Different aspects of technical difficulties and complications encountered in these 5 regions were highlighted. Prevention and management of each potential technical problem were documented and analyzed with the support of current literature review.

\subsection{RESULTS}

The 5 regions of craniomaxillofacial distraction osteogenesis were alveolar, mandibular, cleft maxilla, craniofacial and facial cleft. Different important technical issues and complications were comprehensively highlighted in the discussion section. From the 5 different cases, most technical complications were device related and associated with anatomical limitations and surgical technique. Nevertheless, these complications are preventable and can be appropriately managed. All the documented technical complications and its proposed preventive measures and management are summarized in Table I.

\subsection{DISCUSSION}

\subsection{Alveolar distraction}

The inadequacy of alveolar bone dimension in atrophic mandible or maxilla can be due to the post-ablative procedure or natural bone resorption secondary to loss of teeth. Apart from these conditions, reconstructed jaw with either vascularized or non-vascularized bone graft often produces less than ideal bone dimension particularly in vertical aspect either due to resorption process or the actual nature of the original donor bone. The ultimate aim for alveolar ridge augmentation is to increase the alveolar vertical height and horizontal width prior to dental implant rehabilitation. ${ }^{11,12}$

In alveolar distraction, vector control is important as it determines the final position of the transport segment prior to dental implant placement. Apart from using an internal device with adjustable distraction body angle, temporary denture (Figure $1 \mathrm{~A})$ or orthodontic wire can be used to act as a support to prevent the transport segment from tilting lingually or palatally. ${ }^{11}$ Once the consolidation period has completed, implant insertion can be done with the distractor still intact to the bone to ensure the stability of the distracted segment (Figure 1B).

In reconstructed posterior mandible which requires vertical augmentation, the device can be fixed to face downward with the activation rod protruding out percutaneously to allow ease of activation and cleaning purposes (Figure 1C). As shown in Figure $1 \mathrm{C}$, reinforcement miniplate can be fixed to prevent unfavourable fracture of the inferior mandible during osteotomy.

For short span edentulous alveolar segment particularly at the anterior maxilla, the common problem is the limited area for placement of the device and the area for basal plate fixation is limited due to the presence of anterior nasal spine and nasal floor. When necessary, one arm of the transport plate can be cut and a single arm transport plate is sufficient to carry the small transport bone segment.

\subsection{Mandibular distraction}

In the mandible, the technique can be used as an alternative to sagittal split osteotomy for mandibular advancement in cases such as mandibular hypoplasia in the anterior-posterior direction and obstructive sleep apnea secondary to micrognathia. As the clinical indications often associated with functional and aesthetic outcomes, vector determination is an important technical aspect in mandibular distraction osteogenesis. Apart from the conventional clinical and lateral cephalometric assessment, computer or stereolithographic aided 3-dimensional surgical simulation can be used to assist surgical precision. In most bilateral mandibular distraction cases, ideally, the 2 distraction bodies should be fixed parallel to the occlusal plane, close to the sagittal plane and at the same level with each other. ${ }^{13}$ However, in asymmetric cases, this approach varies as the vector selection should be tailored based on the specific needs of the individual case. Another important intra-operative technical issue is preventing inferior alveolar nerve (IAN) injury during osteotomy. ${ }^{14}$ In our centre, we pre-determine and mark the osteotomy line at the fabricated 3D biomodel and perform a pre-surgical simulation (Figure 2) after identifying the depth of bone circumferential to the IAN canal from cone beam CT (CBCT) image. The acrylic splint is made based on these analyses to minimize nerve injury. Using the splint as a guide intra-operatively, we use a piezo saw to make the cut until it reaches approximately $2 \mathrm{~mm}$ short of the actual depth measured from the CBCT image. The osteotomy is completed with a blunt osteotome. 
Table I

Summary of potential major technical complications in distraction osteogenesis

\begin{tabular}{|c|c|c|c|}
\hline Region & Major technical complication & Prevention & Management \\
\hline \multirow[t]{2}{*}{ Alveolar } & Lingual or palatal tilt & $\begin{array}{l}\text { Temporary denture } \\
\text { Orthodontic wire } \\
\text { Adjustable alveolar device }\end{array}$ & Surgical correction \\
\hline & Fracture of basal bone & $\begin{array}{l}\text { Reinforcement miniplates during } \\
\text { fixation of distractor }\end{array}$ & Surgical fixation \\
\hline \multirow[t]{3}{*}{ Mandible } & Inferior alveolar nerve injury & $\begin{array}{l}\text { Piezo saw + surgical wafer + canal } \\
\text { identification via imaging }\end{array}$ & Neurosurgical repair \\
\hline & $\begin{array}{l}\text { Proximal segment upward } \\
\text { shift }\end{array}$ & Vertical body osteotomy & \multirow{2}{*}{$\begin{array}{l}\text { Surgical correction } \\
\text { If TMJ ankylosis, } \\
\text { condylectomy } \\
\text { Surgical correction }\end{array}$} \\
\hline & Vector control & $\begin{array}{l}\text { Pre-surgical 3D simulation } \\
\text { Parallel positioning of devices } \\
\text { Elastic } \\
\text { Multidirectional device }\end{array}$ & \\
\hline \multirow[t]{2}{*}{ Maxilla } & $\begin{array}{l}\text { Vector control and maxillary } \\
\text { canting }\end{array}$ & $\begin{array}{l}\text { Pre-surgical 3D simulation } \\
\text { Vector guidance splint } \\
\text { Parallel positioning of devices } \\
\text { Elastic }\end{array}$ & Surgical correction \\
\hline & $\begin{array}{l}\text { Mechanical obstruction of co- } \\
\text { ronoid process }\end{array}$ & Pre-surgical simulation & $\begin{array}{l}\text { Surgical correction } \\
+/ \text { - coronoidectomy }\end{array}$ \\
\hline \multirow[t]{6}{*}{ Craniofacial } & $\begin{array}{l}\text { Perforation of halo stabilizing } \\
\text { pin (external device) }\end{array}$ & $\begin{array}{l}\text { Temporal protective mesh } \\
\text { Customized head gear }\end{array}$ & $\begin{array}{l}\text { Surgical removal and } \\
\text { neurosurgical re- } \\
\text { pair }\end{array}$ \\
\hline & Inadequate advancement by & Pre-surgical 3D simulation & Surgical correction \\
\hline & $\begin{array}{l}\text { single (internal or external) } \\
\text { system }\end{array}$ & $\begin{array}{l}\text { Combination of external and inter- } \\
\text { nal system }\end{array}$ & $\begin{array}{l}\text { Conventional osteot- } \\
\text { omy for correc- } \\
\text { tion }\end{array}$ \\
\hline & $\begin{array}{l}\text { Poor compliancy (pediatric } \\
\text { with external device) }\end{array}$ & & \\
\hline & $\begin{array}{l}\text { Neck injury in very young in- } \\
\text { fant with external device }\end{array}$ & $\begin{array}{l}\text { Head gear } \\
\text { Upper limb splint to prevent in- } \\
\text { fant's direct handling }\end{array}$ & \\
\hline & & Cervical splint for neck protection & \\
\hline Facial cleft & $\begin{array}{l}\text { Difficult vector control for } \\
\text { modified fixation of alveolar } \\
\text { distractor }\end{array}$ & Pre-surgical 3D simulation & $\begin{array}{c}\text { Surgical correction } \\
\text { Conventional bone } \\
\text { augmentation }\end{array}$ \\
\hline
\end{tabular}

When dealing with micrognathia secondary to TMJ ankylosis, it is advisable not to resect the ankylosed area prior to distraction phase. This is to allow the ankylosed region to act as a stable basal segment and prevent the proximal segment from moving upward. The resection should be performed during removal of the device instead. A straight vertical osteotomy cut can be used instead of oblique cut to minimized proximal segment to shift upward.

\subsection{Cleft maxillary distraction}

A congenital problem such as in cleft lip and palate causes severe maxillary hypoplasia in the anterior-posterior direction. Distraction osteogenesis has the advantage of achieving massive maxillary advancement compared to conventional Le Fort I osteotomy. Gradual bone formations with simultaneous neo histogenesis produce better longterm stability. ${ }^{15}$

Technically, it is advisable to pre-bend the foot plate of the maxillary device as intra-operative plate bending can be very challenging due to the uneven maxillary bone surface and limited working area, especially at the zygoma region. Apart from reducing the operating time and achieving precise fixation intra-operatively ${ }^{15}$, trial fixation of the device and pre-surgical operative simulation allow the surgeon to assess the maxillary projection thus maximizing the amount of advancement and prevent maxillary canting. The arms of both posterior foot plates need to be correctly in place and not disturbing the movement of the coronoid process during jaw movement.

Vector control is paramount in maxillary distraction osteogenesis to prevent maxillary canting. Apart from pre-operative surgical simulation, vector guidance splint can be used as a guide for distraction vector to be parallel with the mandibular occlusal plane (Figure $3 \mathrm{~A} \& 3 \mathrm{~B}$ ). ${ }^{16}$ This step is important because the vector cannot be changed once the maxillary advancement has reached consolidation phase. In addition, postoperative lateral cephalogram during distraction phase allows direct assessment of the bilateral activation rods position in relation to the occlusal plane thus ensuring correct maxillary projection (Figure 3C). 
Figure 1

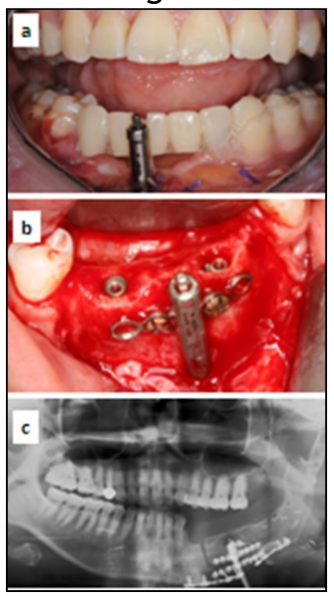

Fig. 1a. Temporary denture can be used to support the activation rod from the lingual pull.

Fig. 1b. Dental implants can be inserted first prior to removal of the distractor in the same procedure as the presence of the distractor

stabilizes the distracted segment.

Fig. 1c. Alveolar distractor fixation at the posterior aspect of the mandible which was turned upside down to allow extraoral rod protrusion. Note the 2 reinforcement miniplates fixed at the weak area of the inferior border of the reconstructed mandible.

\subsection{Craniofacial distraction}

Syndromic craniosynostosis conditions such as Crouzon and Apert syndrome classically presented with hypoplastic facial features which lead to orbital exophthalmia and in severe cases, narrow nasopharyngeal airway secondary to the depressed midfacial components. ${ }^{17}$

The option of either to use only bilateral internal or single external device or a combination of both depends on the clinical and functional indications. Functional factors associated with craniosynostosis conditions include increased intracranial pressure, reduced orbital protection and impaired upper airway need to be comprehensively assessed. Ideally, the technique should be able to restore all the 3 functional aspects.

In severe craniofacial deformity, the application of internal distractors at the zygomatic bones advances the lateral aspects farther than the central midface. The force exerted on the lateral region can be high thus leading to fracture as this region is often hypoplastic thus causing inadequate nasopharyngeal opening at the central region. ${ }^{18}$ Some centers favor a single application of rigid external distractor to achieve the desired midface advancement thus aiming to correct the central midface concavity and increase the upper airway patency. ${ }^{19}$

With regards to the devices application, pre-surgical computer aided with 3D biomodel surgical simulation and pre-bending of footplates (Figure 4AC) can reduce operating time and assist surgical precision. However, its application in infants may not be too practical as the baby may disturb the device and causing the frame to dislodge. Collar splint may be needed in infants to prevent the weight of the rigid external device to injure the
Figure 2

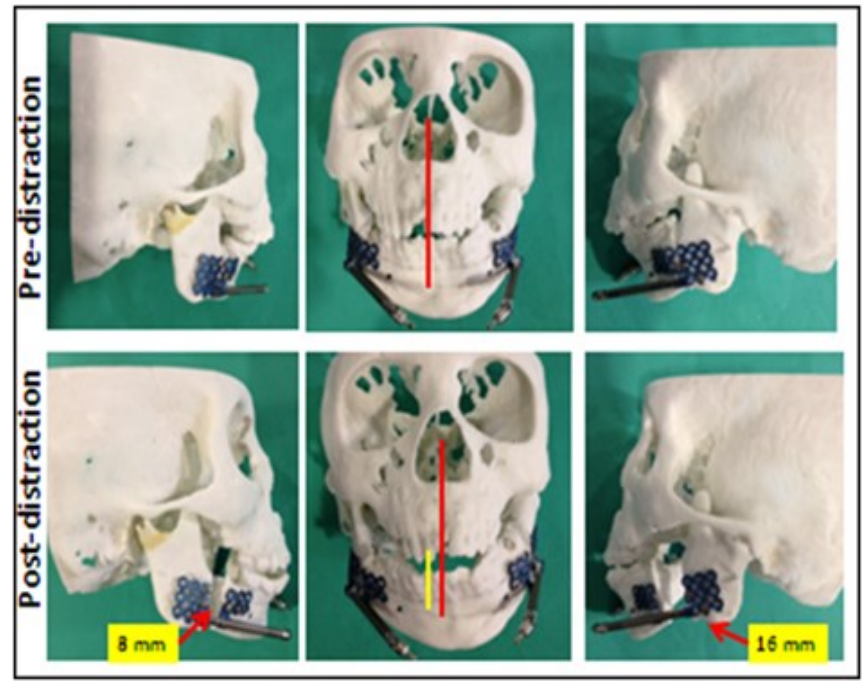

Fig. 2. Mandibular distraction in a case of left TMJ ankylosis with obstructive sleep apnea. The procedure involved uneven distraction amount to advance the mandible and correct the midline. Resection of ankylosed joint was done after consolidation period is complete.

neck. Post-operative technical issues such as loose stabilizing pins and frame migrations have been reported. ${ }^{20,21}$ A pre-fabricated temporal protective mesh can be used to prevent intra-cranial pin perforation (Figure 4D).

Combination use of both internal and external devices can cause an increase in the cost and morbidity as there will be additional procedures, longer operating time and increase of wound on the skin communicating to the activation points. Nevertheless, the advantage of combined use of internal and external devices is, it maximizes the advancement on both central and lateral facial aspect. $^{22}$ and if the external device dislodges, there is still an internal device to support and carry the distracted segment forward.

\subsection{Facial cleft distraction}

The defect in the facial bone area is challenging as the indication is to level up the eyeball while maintaining its normal projection. The surgical access is small thus making the working area very limited and the patient will be subjected to heavy soft tissue manipulation that can cause a hematoma. The infraorbital rim is very thin and the transport segment has no pedicle thus risking it to resorption. The choice of device is limited and one option is to modify the application of alveolar distractor by turning it upside down in order to raise the infraorbital rim (Figure 4E-F).

The extent of the osteotomy should include both infraorbital rim and the orbital floor as well in order to support the eyeball. When the infraorbital rim is cut and separated, orbital fat may herniate and disturb the working area. As such, it is important to ensure that the fat is not trapped in between the distracted region as this may lead to 
malunion. A post-operative hematoma is also an issue as it causes discomfort and potential risk to the affected eye.

\subsection{PREVENTING AND MANAGING TECHNICAL COMPLICATIONS}

In general, technical complications can be either device or non-device related. These include device fracture, loose fixation and incorrect vector. ${ }^{11}$ Due to the presence of communication between wound and external environment via the activation rod, the risk of infection is high. Nevertheless, infection is often localized and easy to manage. Post-operative wound care is essential during distraction phase. In pediatric craniofacial distraction, extra care should be given especially in minimizing their physical activity to prevent any unwanted incident especially to the protruding internal distraction rod or the external device. As intra-cranial perforation of stabilizing pins have been reported, ${ }^{20,21}$ we use either a pre-fabricated temporal mesh (Figure 4D) or custom made protective head gear to prevent such complication at the very thin temporal bone area. The activation technique, distraction schedule, and its protocol must be clearly taught to the guardians and appropriate documentation is necessary to ensure the targeted outcome is achieved.

Non-device related complications which are associated with technical aspect include unfavourable fracture of bone segment either at basal or transport segment and nerve injury in the case of mandibular advancement. Reinforcement plates can be fixed at the basal pone to support the weak bony points (Figure $1 \mathrm{C}$ ) and as discussed in the mandibular distraction segment earlier, pre-surgical CBCT assessment, fabrication of marking splint and piezo cutting tool minimize the risk of IAN injury. Suggestions for prevention and management of technical complications based on literature and our practice are summarized in Table I.

From an Islamic perspective, Prophet Muhammad in a hadith, once quoted "For every disease there is a medicine, and if that medicine is applied to the disease, he will recover by Allah's Leave." And He (s.a.w.) also said: "Allah has not sent down any disease but He has also sent down the cure; the one who knows it, knows it and the one who does not know it, does not know it." Based on the above, it is clear that Islamic teachings fully support the use of all forms of treatment because the underlying principle is that Allah has created cures for all diseases. The key is to ensure that the right type of treatment is applied for the right type of ailment. Therefore, it is crucial to critically analyze the treatment done and ensure all treatment delivered are well planned and managed properly to prevent complications.

This is also an application of Islamic concept of Ihsan, in which the pursue of excellence in everything that Muslims do. Through the concept of Ihsan, all Muslims are to strive for the best in everything that they are involved in, including excellence in surgical planning and its management.

\subsection{CONCLUSION}

Distraction osteogenesis is very technical dependent but can be reliably considered as an alternative to the conventional surgical procedure for bone augmentation and superior segmental advancement. Potential technical complications are preventable and should be managed as early as possible to ensure a successful surgical outcome.

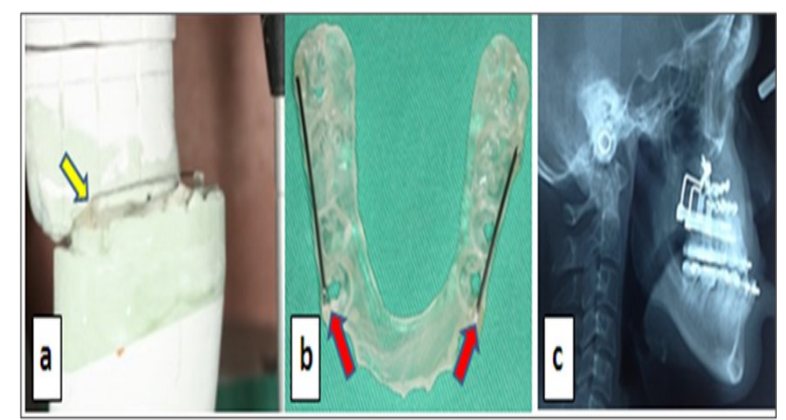

Fig. 3a Fabrication of vector guidance splint (yellow arrow) based on the mounted models.

Fig. 3b Vector guidance splint is fabricated with 2 straight wires (red arrows) attached to it to guide parallel fixation of bilateral distraction devices to the mandibular occlusal plane.

Fig. 3c. Radiographic assessment of maxillary distractor body positions in relation to occlusal plane during intra-distraction phase.
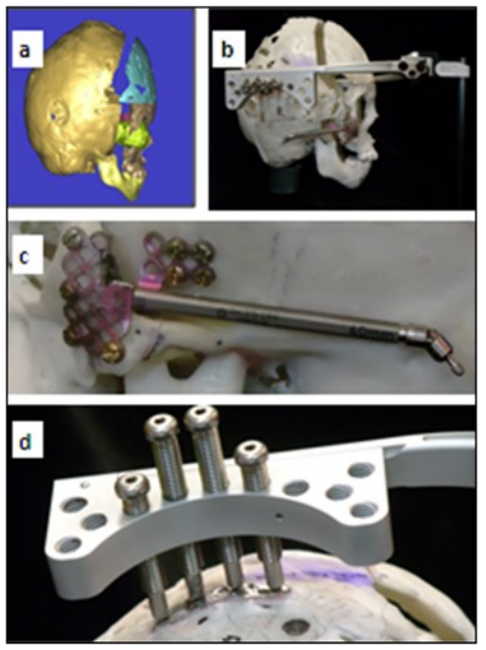

Fig. 4. Pre-surgical preparation in craniofacial DO: a) Computer aided surgical simulation b) 3D biomodel surgical simulation and trial activation c) Pre-bent foot plates d) Pre-fabricated temporal protective titanium mesh for external stabilizing pins to prevent perforation. e) Surgical planning and f) trial activation of modified alveolar distractor in facial cleft case.

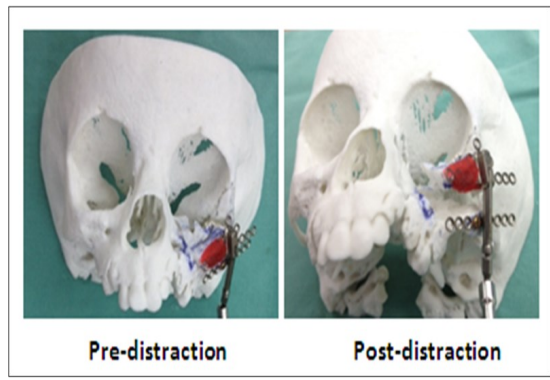

Fig. 5. 


\section{References}

1. Codivilla A. On the means of lengthening in the lower limbs, the muscles, and tissues which are shortened through deformity. Am J Orthop Surg 1905;2:353-69.

2. Ilizarov GA. The principles of Ilizarov Method. Bull Hosp Jt Dis Orthop Inst 1988;48:1-11.

3. Ilizarov GA. The tension-stress effect on the genesis and growth of tissues. Part I. The influence of stability of fixation and soft tissue preservation. Clinical Orthop Rel Res 1989;238:249-81.

4. Ilizarov GA. The tension-stress effect on the genesis and growth of tissues: Part II. The influence of the rate and frequency of distraction. Clinical Orthop Rel Res 1989;239:263-85.

5. Snyder CC, Levine GA, Swanson HM, Browne EZ. Mandibular lengthening by gradual distraction: preliminary report. Plast Reconstr Surg 1973;51:506-8.

6. Michieli S, Miotti B. Lengthening of mandibular body by gradual surgical-orthodontic distraction. J Oral Surg 1977;35:187-92.

7. McCarthy JG, Schreiber J, Karp N, Thorne CH, Grayson $\mathrm{BH}$. Lengthening the human mandible by gradual distraction. Plast Reconstr Surg 1992;89:1-8.

8. McCarthy JG, Stelnicki EJ, Mehrara BJ, Longaker MT. Distraction osteogenesis of the craniofacial skeleton. Plast Reconstr Surg 2001;107:1812-27.

9. Adolphs N, Ernst N, Menneking H, Hoffmeister B. Significance of distraction osteogenesis of the craniomaxillofacial skeleton - A clinical review after 10 years of experience with the technique. J Craniomaxillofac Surg. 2014(doi:10.1016/j.jcms.2014.01.018.)

10. Natu SS, Ali I, Alam S, Giri KY, Agarwal A, Kulkarni VA. The biology of distraction osteogenesis for correction of mandibular and craniomaxillofacial defects: A review. Dent Res J (Isfahan) 2014;11:16-26.

11. Hariri F, Chua HDP, Cheung LK. Distraction osteogenesis for the cranio-maxillofacial region (III): A compendium of devices for the dentoalveolus. J Oral Maxillofac Surg Med Pathol 2013;25:101-14.

12. Yamauchi K, Takahashi T, Nogami S, Kataoka Y, Miyamoto I, Funaki. Horizontal alveolar distraction osteogenesis for dental implant: long-term results. Clin Oral Implants Res 2013;24:563-8.

13. Walker DA. Management of severe mandibular retrognathia in the adult patient using distraction osteogenesis. J Oral Maxillofac Surg 2002;60:1341-6.

14. Master DL, Hanson PR, Gosain AK. Complications of mandibular distraction osteogenesis. J Craniofac Surg 2010;21:1565-70.

15. ChuaHD, HäggMB, Cheung LK. Cleft maxillary distraction versus orthognathic surgery-which one is more stable in 5 years? Oral Surg Oral Med Oral Pathol Oral Radiol
Endod 2010;109:803-14.

16. Cheung LK, Chua HD, Lo J, Luk HW. Vector guidance splint for internal maxillary distraction. J Oral Maxillofac Surg. 2007 Sep;65(9):1852-6.

17. Posnick JC, Ruiz RL, Tiwana PS. Craniofacial dysostosis syndromes: stages of reconstruction. Review article. Oral Maxillofac Surg Clin N Am 2004;16:475-91.

18. Gosain AK, Santoro TD, Havlik RJ, Cohen SR, Holmes RE. Midface distraction following Le Fort III and monobloc osteotomies: Problems and solutions. Plast Reconstr Surg 2002;109:1797-808.

19. Witherow H, Dunaway D, Evans R, Nischal KK, Shipster C, Pereira V, et al. Functional outcomes in monobloc advancement by distraction using the rigid external distractor device. Plast Reconstr Surg 2008;121:1311-22.

20. Nout $E$, Wolvius EB, van Adrichem LN, Ongkosuwito EM, van der Wal KG. Complications in maxillary distraction using the RED II device: a retrospective analysis of 21 patients. Int J Oral Maxillofac Surg 2006;35:897902.

21. Breugem CC, Bush K, Fitzpatrick DF. Le Fort III rigid external distraction complicated by intracranial movement of halo fixation pins. Cleft Palate Craniofac J 2008;45:332-6

22. Nishimoto S, Oyama T, Tei S, Seike S, Nagashima T, Kawai K, et al. "Bibloc advancement" with a combination of internal and external distracters. J Craniofac Surg 2012;23:1444-7. 